\title{
INTERPRETIVE SUMMARIES, FEBRUARY 2012
}

Invited review: Genomic analysis of data from physiological studies. By Garrick et al., page 499. Physiology is concerned with elucidating the functions of living organisms and their organs or tissues. Early studies determined the functions of particular organs, such as the mammary gland. Later studies identified physiological differences between animals in different stages of life or in different environmental circumstances, sometimes to the level of individual genes. Genomics addresses the entire genome, and has empowered a new phase in physiology research that focuses on identifying and studying the genes that account for variation in performance by causing physiological differences to develop. This knowledge will improve our understanding of biology and may lead to novel strategies to manipulate animal performance.

Manufacture of Fior di Latte cheese by incorporation of probiotic lactobacilli. By Minervini et al., page 508. Probiotic lactobacilli were tested for heat resistance. Selected Lactobacillus delbrueckii ssp. bulgaricus SP5 and Lactobacillus paracasei BGP1 were used for the manufacture of Fior di Latte (high-moisture Mozzarella) cheese. Both selected probiotics in Fior di Latte cheeses were at values of cell density above the minimum required for food and beverages containing probiotic bacteria. Microbiological, compositional, biochemical and sensory analyses showed that the use of selected SP5 and BGP1 strains enhanced flavor formation and shelf-life of Fior di Latte cheeses.

Comparison of the metabolic profiles of noncoagulating and coagulating bovine milk. By Harzia et al., page 533. Milk coagulation ability has been widely studied, but the factors explicitly explaining the noncoagulation of milk remain elusive. The aim of this study was to use liquid chromatography mass-spectrometry-based metabolomic profiling to characterize coagulating and noncoagulating milks, and to pinpoint the potential markers identifying their differences. If the detected metabolic markers such as carnitine and oligosaccharides are alterable by the means of feeding or genetic selection, this would provide an economic advantage to the dairy industry.

In vivo methods for testing allergenicity show that high hydrostatic pressure hydrolysates of $\beta$-lactoglobulin are immunologically inert. $B y$ López-Expósito et al., page 541. The aim of this work was to evaluate the allergenicity of $3 \beta$-lactoglobulin hydrolysates produced under atmospheric or highpressure conditions. The 3 tested hydrolysates showed an abrogated allergenicity as revealed by the absence of anaphylactic symptoms in a milk allergy mouse model.
We also demonstrated that the peptides present in the hydrolysates had lost their ability to cross-link 2 human immunoglobulin E antibodies. The orally sensitized mouse model is a useful tool to address the in vivo allergenicity of novel milk formulae, and demonstrates the safety of hydrolysates produced under high-pressure conditions.

Effect of high pressure treatment on denaturation of bovine lactoferrin and lactoperoxidase. By Mazri et al., page 549. Lactoferrin and lactoperoxidase have biological activities that may provide health benefits to consumers. However, these proteins are vulnerable to potentially denaturing conditions during processing. High-pressure treatment is a nonthermal technology that can be used for food preservation. The effect of high-pressure treatment on the denaturation of lactoferrin and lactoperoxidase in milk, whey, and buffer was studied over a pressure range from 450 to 700 $\mathrm{MPa}$ at $20^{\circ} \mathrm{C}$ and kinetic parameters were determined. The design of pressure treatments should consider these kinetic parameters to preserve the integrity of these whey proteins and thus, their biological function.

Survival of lactic acid bacteria from fermented milks in an in vitro digestion model exploiting sequential incubation in human gastric and duodenum juice. By Faye et al., page 558. The survival of lactic acid bacteria (as washed cells or in fermented milk) was investigated under conditions similar to human digestion using human gastric and duodenal juices, and with traditional methods using acidic conditions and bile salts. The Lactobacillus strains showed the highest survival rate. However, Enterococcus hirae and some of the Lactococcus strains benefited significantly from the fermented milk. The human model digestive system comprises an in vitro testing regimen suitable for evaluation of the survival of candidate probiotic bacteria in human digestion.

Proteomic analysis and immunodetection of the bovine milk osteopontin isoforms. By Bissonnette et al., page $56 \%$. Osteopontin is an immunostimulatory protein secreted in substantial amounts in bovine milk. Whereas human milk contains only one protein, several isoforms have been found in bovine milk. Human isoforms of the protein have previously been reported as the product of alternative spliced transcripts associated with metastasis. In the present study, the genomic and proteomic analysis of bovine osteopontin have confirmed the absence of alternative splicing. Milk-secreted bovine milk contains cleaved and mature proteins, and both were characterized by immunodetection and mass spectroscopy. 
Proteomic profiling of microbial transglutaminase-induced polymerization of milk proteins. $B y$ Hsieh and Pan, page 580. This manuscript describes our recent work on the proteomic analysis of microbial transglutaminase (MTGase)-induced polymerization of milk proteins during incubation. The results indicate that MTGase-induced polymerization occurred earlier for $\beta$-casein and $\kappa$-casein isomers than for other milk proteins. Other milk proteins that were polymerized following incubation with MTGase included $\alpha_{\mathrm{S1}^{-}}$ casein, $\alpha_{S_{2}}$-casein, $\beta$-lactoglobulin, $\alpha$-lactalbumin, and a fraction of serum albumin. Our results indicate that a proteomics-based approach is a useful and effective tool for the analysis of milk proteins affected by MTGase.

Determination of melamine in milk and dairy products by high performance liquid chromatography. By Filazi et al., page 602. This is the first study to confirm the existence of melamine in milk and dairy products in Turkey. Consumption of foods containing these low levels of melamine does not constitute a health risk for consumers.

Short communication: A comparative analysis of recombinant chymosins. By Vallejo et al., page 609. The present work represents a comparative study of the recombinant chymosins described in the last few years. Here we characterize the biochemical and kinetic parameters of these enzymes, using bovine chymosin as reference. Recombinant goat chymosin displayed the best catalytic efficiency, leading us to propose this enzyme as a serious alternative to bovine chymosin, the commonly used chymosin in the cheese-making industry.

Short communication: Annatto in Cheddar cheese-derived whey protein concentrate is primarily associated with milk fat globule membrane. By Zhu and Damodaran et al., page 614. The yellow/brown color of whey protein concentrate manufactured from Cheddar cheese whey is due to annatto used in making colored Cheddar cheese. This undesirable color is often removed by treating the Cheddar cheese whey with bleaching agents. However, this practice changes the flavor and destroys the nutritive value of whey proteins. In this paper, we show that annatto in Cheddar cheese whey is mainly associated with the milk fat globule membrane particles, and removal of these particles using a new process produces a whey protein product that is white.

Immunization of adult dairy cattle with a new heat-killed vaccine is associated with longer productive life prior to cows being sent to slaughter with suspected paratuberculosis. By Alonso-Hearn et al., page 618. This study provides evidence that vaccination of adult cows with a new heat-killed $M y$ cobacterium avium ssp. paratuberculosis (Map) vaccine was an effective strategy in reducing bacterial shedding in the feces and bacterial colonization of gut tissues compared with nonvaccinated animals. As a result, the benefits of the vaccination were a reduction in premature culling due to paratuberculosis and an increase in the carcass weights of infected animals with severe histopathological lesions.

Sickness behavior in dairy cows during Escherichia coli mastitis. By Fogsgaard et al., page 630. A study was conducted to evaluate sickness behavior of dairy cows infected with Escherichia coli mastitis. Feeding, rumination, idling, and self-grooming behavior were altered during the acute phase of mastitis compared with preinfection days, suggesting that the animals experienced underlying motivational changes and that dairy cows show classic signs of illness behavior in the hours after intramammary challenge with E. coli. Knowledge about sickness behavior in dairy cows can be used to evaluate animal welfare, to improve disease detection, and to increase the understanding of the potential needs of dairy cows suffering from mastitis.

Increased fertility in lactating dairy cows resynchronized with Double-Ovsynch compared with Ovsynch initiated $32 \mathrm{~d}$ after timed artificial insemination. By Giordano et al., page 639. Improved programs are needed to resynchronize cows that are not pregnant after a previous artificial insemination. In this study of resynchronized breedings, cows resynchronized with Double-Ovsynch had greater fertility than cows resynchronized with an Ovsynch protocol initiated $32 \mathrm{~d}$ after a previous timed artificial insemination. Greater fertility resulted from an increased percentage of cows with a functional corpus luteum at initiation of the second Ovsynch protocol, which improved overall synchrony of the double-Ovsynch protocol. These results are useful for development of practical reproductive management programs to improve fertility of dairy cows during resynchronization protocols.

Effect of dietary copper source on response to coliform mastitis in dairy cows. By Scaletti and Harmon, page 654. Environmental mastitis, a costly disease in dairy cattle, is unresponsive to antibiotics, so preventive strategies are crucial. Copper is a micronutrient effective in combating mastitis. Traditionally, inorganic forms of essential microminerals have been fed. Recent studies in many species show that organic mineral forms are more efficiently retained in tissue. We examined the effects of organic versus inorganic copper in reducing the incidence and severity of clinical mastitis and found that cows fed the organic form tended to have improved milk yield, clinical udder score, and bacterial count. 
The effect of clinical lameness on liveweight in a seasonally calving, pasture-fed dairy herd. $B y$ Alawneh et al., page 663. This paper investigated the effect of lameness on liveweight in a seasonally calving, pasture-fed New Zealand dairy herd. After controlling for the effect of week in milk, parity, liveweight at calving, breed, calendar month, and season, the liveweight of lame cows decreased for up to $3 \mathrm{wk}$ before diagnosis and for up to 4 wk after treatment. The results from this study demonstrate how liveweight records for individual animals can be used to enhance a herd manager's ability to detect lame cows and present them for treatment. The methods presented in this paper provide a first attempt to show how daily liveweight monitoring might be used as a tool for early detection of lameness in dairy cattle.

Effects of plane of nutrition and feed deprivation on insulin responses in dairy cattle during late gestation. By Schoenberg et al., page 670 . Responses to glucose and insulin in prepartum dairy cattle are affected by prior plane of nutrition and feed deprivation. Negative energy balance caused either by diet or feed deprivation resulted in slower clearance of glucose and larger responses in circulating free fatty acids. Feed deprivation also had a large effect on insulin secretion in response to a glucose challenge. These results indicate that negative energy balance can have differential effects on glucose and fatty acid metabolism which should be taken into account during times of metabolic adaptation in dairy cattle.

Changes in serum pregnancy-associated glycoprotein, pregnancy-specific protein $\mathrm{B}$, and progesterone concentrations before and after induction of pregnancy loss in lactating dairy cows. By Giordano et al., page 683. Temporal changes in pregnancy-associated glycoprotein (PAG), pregnancy-specific protein B (PSPB), and progesterone concentrations before and after induced pregnancy loss were evaluated. Serum PAG concentrations in pregnant cows differed from those in nonpregnant cows by $27 \mathrm{~d}$ after timed artificial insemination (TAI), whereas serum PSPB concentrations in pregnant cows differed from those in nonpregnant cows by $22 \mathrm{~d}$ after TAI. In cows with induced pregnancy loss, both PAG and PSPB dynamics were characterized by a steady decrease after treatment, with no major differences between models of pregnancy loss.

Hormones, metabolites, and reproduction in Holsteins, Jerseys, and their crosses. By Brown et al., page 698. Holsteins, Jerseys, and their crosses in first $(\mathrm{n}=157)$ and second $(\mathrm{n}=107)$ lactation were observed to determine if reproduction, insulin-like growth factor 1 (IGF-1), insulin, nonesterified fatty acids (NEFA), and milk production differed between genetic groups. Days open and service number were affected by genetic group. The genetic group by week interaction affected NEFA concentrations. Insulin was affected by genetic group. The genetic group by lactation number interaction affected IGF-1 concentrations. Genetic group affected hormones and metabolites, which may partially explain differences in reproductive measures and milk yield.

Effect of postcalving serum nonesterified fatty acids concentration on the functionality of bovine immune cells. By Ster et al., page 708. In this research, we investigated the relationship between serum composition and immune cell functionality. Peripheral blood mononuclear cells incubated with serum harvested in the first week of lactation had reduced ability to proliferate and to release interferon- $\gamma$, a finding that appears linked to the increased concentration of nonesterified fatty acids. This suggests that approaches that limit the increase in nonesterified fatty acids during the transition period likely reduce periparturient immunosuppression.

Effect of intramammary infection on milk electrical conductivity in Murciano-Granadina goats. By Diaz et al., page 718. Measurements of electrical conductivity (EC) of milk are used in mastitis detection in cows due to its low cost, possibility of automation, and rapid diagnosis, but literature about its use in goats is scarce. In this study, the effect of the establishment of intramammary infection on EC of goat milk by gland was studied by means of daily measurements. A significant effect of infection on EC in the affected glands was observed, which suggests that the use of systems based on daily readings of EC could be useful in detection of intramammary infection in goats.

Association between bovine leukemia virus, production, and population age in Michigan dairy herds. By Erskine et al., page 72\%. Bovine leukemia virus (BLV) is an infectious disease that causes lymphosarcoma in a small percentage of infected cattle. However, the effect of this disease on cattle with subclinical infections is controversial. In this study, the prevalence of BLV in 104 dairy herds in Michigan was determined by detecting anti-BLV antibodies in milk by enzyme-linked immunosorbent assay. A significant association between higher herd prevalence of BLV and reduced milk production was determined. Additionally, dairy herds with a higher prevalence of BLV had a lower proportion of older cows ( $>3$ lactations) within herd populations. Our results provide evidence that BLV infection is associated with herd-level economic effects in high-performing dairy herds.

Detection of hoof lesions using digital infrared thermography in dairy cows. By Alsaaod and 
Büscher, page 735. With increasing herd size of dairy farms, an automated lameness detection system would be very useful for the dairy industry. A thermal camera was used to measure coronary band temperature as a means of detecting lesions in the hind limbs in dairy cattle during routine hoof trimming. Surface temperature of the lame limb increased when a hoof had a lesion.

Effects of synchronization treatments on ovarian follicular dynamics, corpus luteum growth, and circulating steroid hormone concentrations in lactating dairy cows. By Herlihy et al., page 743. Effective regulation of the corpus luteum, ovulatory follicle development, and periovulatory circulating steroid hormone concentrations is critical for optimizing responses to synchronization treatments. This study compared ovarian follicular dynamics, corpus luteum growth, and circulating steroid hormone concentrations in lactating dairy cows treated to synchronize estrus or ovulation. Progesterone supplementation during synchronization and ovulation induction with $\mathrm{GnRH}$ on the day before timed artificial insemination affected ovulatory follicle size and periovulatory circulating concentrations of progesterone and estradiol. No differences in postovulatory progesterone concentrations or luteal volume were observed.

Short communication: Supplementing grape marc to cows fed a pasture-based diet as a method to alter nitrogen partitioning and excretion. By Greenwood et al., page 755. The public is increasingly interested in methane emissions and nitrogen leaching from intensive livestock production. Use of byproducts as a dietary supplement in livestock rations can have a lower environmental impact compared with some other purpose-grown or processed supplements. Moreover, inclusion of dietary byproducts with beneficial chemical properties, such as condensed tannin content, could be a useful method to decrease urinary $\mathrm{N}$ excretion. In the current study, the use of grape marc as a dietary supplement for nonlactating dairy cattle was found to alter $\mathrm{N}$ partitioning.

Short communication: Pheromonicin-SA affects mRNA expression of toll-like receptors, cytokines, and lactoferrin by Staphylococcus aureus-infected bovine mammary epithelial cells. By Zhu et al., page 759. Pheromonicin-SA is a newly developed engineered multidomain peptide that has a bactericidal effect against Staphylococcus aureus. The objective of this study was to characterize innate immune responses by Staph. aureus-stimulated bovine mammary epithelial cells following treatment with pheromonicin-SA. Real-time polymerase cahin reaction was used to quantify toll-like receptor (TLR) 2 and TLR4, interleukin (IL)-1 $\beta$, IL-6, IL-8, tumor necrosis factor-alpha $(\mathrm{TNF}-\alpha)$, and lactoferrin. The results indicate that pheromonicin-SA may be of value as an antibiotic in promoting innate immune responses by Staph. aureus-infected bovine mammary epithelial cells.

Defining ruminal and total-tract starch degradation for adult dairy cattle using in vivo data. By Patton et al., page 765. Large amounts of grain are fed to dairy cows to improve energy balance and enhance microbial protein production to support high milk production. Corrections to calculation methods are proposed to more accurately predict the amount of starch digested in the rumen and intestinal tract. This could lead to more accurate prediction of energy provided by dietary starch as well as greater precision in the prediction of the amount of microbial protein produced. This, in turn, should lead to more efficient rations and better grain utilization.

Preweaning milk replacer intake and effects on long-term productivity of dairy calves. By Soberon et al., page 783. Dairy calf nutrition and management decisions have been driven by least-cost approaches, especially with respect to the amount of liquid feed offered prior to weaning. This study was conducted to determine the relationship, if any, between the amount of nutrients consumed from milk replacer before weaning and the milk-producing ability of the animal once she calved. These data demonstrate that lactation performance of the calf can be influenced by early-life nutrient intake.

Fatty acid composition and bacterial community changes in the rumen fluid of lactating sheep fed sunflower oil plus incremental levels of marine algae. By Toral et al., page 794. A more complete understanding of changes in ruminal microbial ecology that accompany alterations in ruminal biohydrogenation may provide further insight into the mechanisms underlying changes in milk fat composition. In this experiment, supplementation of dairy ewe diets with sunflower oil alone or in combination with marine algae altered the abundance of specific fatty acids in rumen fluid but this was not associated with changes in ruminal bacteria known to be capable of biohydrogenation. However, certain bacterial groups detected exhibited variations in their relative frequency consistent with a potential role in ruminal biohydrogenation.

Nutrient demand interacts with grass particle length to affect digestion responses and chewing activity in dairy cows. By Kammes and Allen, page $80 \%$. Orchardgrass was chopped long $(19 \mathrm{~mm})$ or short $(10 \mathrm{~mm})$, ensiled, and included in total mixed rations at 50\% (dry matter basis) as the sole source of forage. Increasing grass particle length decreased feed intake, increased chewing time, and increased ruminal 
starch digestion. Grass particle length did not affect milk yield, milk composition, or rumen $\mathrm{pH}$. When orchardgrass silage was the only source of forage in the diet, increasing chop length did not adversely affect productivity.

Effects of replacing canola meal as the major protein source with wheat dried distillers grains with solubles on ruminal function, microbial protein synthesis, omasal flow, and milk production in cows. By Chibisa et al., page 824. Wheat-based distillers grains with solubles (W-DDGS) is now widely available for feeding dairy cows in western Canada. A study was conducted to determine the effects of replacing canola meal (CM; a commonly used protein supplement in western Canadian dairy cow diets) with W-DDGS on rumen function and milk production. Substituting CM with W-DDGS had no effect on rumen function, but it increased feed intake and milk production.

Effects of varying rates of tallgrass prairie hay and wet corn gluten feed on productivity of lactating dairy cows. By Rezac et al., page 842. Wet corn gluten feed (WCGF), a coproduct of wet milling, is a highly digestible fiber source that can be incorporated into lactating dairy cattle rations in place of other ingredients that provide fiber, protein, and energy. Although WCGF contains a large amount of fiber, dairy cows still require forage to stimulate chewing and maintain healthy digestive function. Diets with high inclusion rates of WCGF that also included tallgrass prairie hay were compared with a control diet containing corn silage and alfalfa as fiber sources. The experimental diet with the highest prairie hay inclusion rate resulted in efficiencies and milk components that did not differ significantly from those of the control diet.

Short communication: Varying dietary dry matter concentration through water addition: Effect on nutrient intake and sorting of dairy cows in late lactation. By Fish and DeVries, page 850. This study was conducted to determine if feed sorting can be reduced and nutrient consumption limited in latelactation cows through water addition to a total mixed ration (TMR) formulated for high production. The treatment diets averaged (1) $62 \%$ dry matter (DM) and (2) $52 \% \mathrm{DM}$. The results indicate that adding water to a TMR may change the DM distribution and starch content of ration particles, possibly contributing to less sorting for the smallest ration particles. Water addition did not limit feed intake in late lactation cows, and thus had no effect on the efficiency of production.

Short communication: Kelp taste preferences by dairy calves. By Erickson et al., page 856. Kelp meal is often added to feeds for dairy cattle and is thought to increase feed intake. Research is lacking on the effects of adding kelp meal to calf starter grain on palatability. The current study evaluated the taste preference of graded amounts of kelp meal on preference by calves. Calves preferred calf starter that did not contain kelp meal.

Validation of single nucleotide polymorphisms associated with milk production traits in dairy cattle. By Chamberlain et al., page 864. Single nucleotide polymorphisms (SNP) previously found to be associated with milk production traits in dairy cattle, including in genes hypothesized to be in pathways affecting milk production, were validated in a new population. In this study, 72 of $423 \mathrm{SNP}$ were associated with one or more milk production traits and were therefore considered validated. An over-representation of the SNP were located on chromosome 20 and a multi-trait analysis was performed.

Imputation of genotypes with low-density chips and its effect on reliability of direct genomic values in Dutch Holstein cattle. By Mulder et al., page 876. Low-density single nucleotide polymorphisms (SNP) chips make genotyping of many more cows and bulls feasible. Imputation of SNP to the 50k $(\sim 50,000$ SNP) chip can increase reliability of direct genomic values (DGV). The aim of this study was to investigate effects of marker densities and imputation methods on accuracy of imputation and reliability of DGV. With 3,000 SNP, the increase in reliability of DGV compared with a pedigree index was 80 to $90 \%$ of the increase obtained with DGV based on the 50k chip.

Accuracy of noninvasive breath methane measurements using Fourier transform infrared methods on individual cows. By Lassen et al., page 890. Emission of greenhouse gases is a great concern today. In this study, we evaluated a method for individual recording of methane production from large numbers of dairy cows. The measurements are based on Fourier transform infrared (FTIR) analysis of breath from cows during visits to feeding stations. We found that 22 to $46 \%$ of the total variation was attributable to individual cows differences. Other components in breath can be measured simultaneously. This technique has high capacity, making it suitable for large-scale, on-farm recording of methane useful to improve management and for genetic evaluation

Genomic associations with somatic cell score in first-lactation Holstein cows. By Wijga et al., page 899. The present study aimed to identify genomic regions that contribute to genetic variation in somatic cell score, a trait generally used as an indicator for mastitis. Three regions contributing to genetic variation in 
somatic cell score were detected, which were located on chromosomes 4, 6, and 18. More knowledge on genetic control of somatic cell score not only provides more insight into the genetic value of an animal, but it may also help to find genes for mastitis resistance. Identification of genes is important for understanding the genetic mechanisms leading to mastitis and the discovery of targets for mastitis therapeutics.

Genomic prediction for the Nordic Red Cattle using one-step and selection index blending. $B y$ Su et al., page 909. Accuracies of genomic predictions are expected to be improved by combining various information sources. This study investigated reliabilities of genomic prediction for 15 traits in Nordic Red. Using information of genotyped bulls alone, reliability of direct genomic breeding value (DGV) for bulls without daughter records was $11.0 \%$ higher than conventional pedigree index (PI). The further gain was $0.9 \%$ using a selection index combining DGV and PI. When applying a one-step blending model, which used information of genotyped and nongenotyped animals simultaneously, reliability of genomic prediction was $1.3 \%$ higher than DGV.

Short communication: Fertility, somatic cell score, and production of Normande $\times$ Holstein, Montbéliarde $\times$ Holstein, and Scandinavian Red $\times$ Holstein crossbreds versus pure Holsteins during their first 5 lactations. By Heins and Hansen, page 918. The reduction of fertility of pure Holstein cows has resulted in global interest in crossbreeding of dairy cattle. The Normande $\times$ Holstein, Montbéliarde $\times$ Holstein, and Scandinavian Red $\times$ Holstein crossbreds in 6 commercial herds with high mean production in California had significant advantages over pure Holstein cows for fertility during their first 5 lactations. Although mean somatic cell score across the 5 lactations were similar for Normande $\times$ Holstein crossbreds and pure Holstein cows, the Montbéliarde $\times$ Holstein and Scandinavian Red $\times$ Holstein crossbreds had significantly lower somatic cell score than the pure Holstein cows. All 3 types of crossbred cows had reduced 305-d projected fat plus protein production compared with their pure Holstein herdmates across the first 5 lactations, but the magnitude of the difference from pure Holstein cows was small for the Montbéliarde $\times$ Holstein and Scandinavian Red $\times$ Holstein cows. Therefore, Montbéliarde and Scandinavian Red are candidate breeds for crossbreeding with the Holstein breed to improve the fertility and udder health of dairy cows in herds with high mean production.

Short communication: Is crossbreeding only beneficial in herds with low management level? By Kargo et al., page 925. The economic benefit of cross- breeding has been well known for many years. However, a myth exists that crossbreeding is most beneficial in herds with a low level of management. Our study did not support this myth, because heterosis effects for milk, fat, and protein yield were lowest in herds with a low production level and largest in herds with an intermediate production level. We therefore claim that crossbreeding is beneficial for all dairy producers and not only for farmers with low management or production levels.

Estimating efficiency in automatic milking systems. By Castro et al., page 929. Data from 34 automatic milking system units in 29 Galician dairy farms were analyzed to determine the system capacity on each farm. The maximum number of milked cows was estimated to maintain the levels of work efficiency. Current throughput per automatic milking unit could be increased from 53 to 69 cows per day without negative effects on milking traits and with a substantial increase in the amount of milk collected annually. This increase may help the farmers optimize the use of the automatic milking system and recover their high investment costs more quickly.

Ability of commercially available dairy ration programs to predict duodenal flows of protein and essential amino acids in dairy cows. $B y P a$ checo et al., page 937. The potential exists to reduce nitrogen excretion to the environment and increase milk protein production by reducing crude protein intake and balancing for amino acids (AA). Adoption of this nutritional strategy, however, might have been slowed because of concerns that ration balancing programs may overestimate AA delivered, may perform poorly on certain types of diets, or inadequate prediction of $\mathrm{AA}$ supply might result in a ration deficiency of a particular AA or total protein, resulting in lower production. Although these concerns are valid, this analysis showed that commercially available dairy nutrition programs can adequately predict duodenal flows of total protein and essential AA in most cases. Use of the more accurate models should allow for more stringent balance of protein and AA of dairy rations for efficient milk production.

Stay-green ranking and maturity of corn hybrids: 1. Effects on dry matter yield, nutritional value, fermentation characteristics, and aerobic stability of silage hybrids in Florida. By Arriola et al., page 964. This study examined the influence of dry matter at harvest, stay-green ranking, and hybrid source on the nutritive value and fermentation of corn silage. Effects of stay-green ranking on nutritive value varied with the source of the hybrid. Higher stay-green rankings were associated with greater stover moisture 
concentration but this did not affect silage quality. The digestible dry matter yield of the hybrids was greatest when they were harvested at $37 \%$ dry matter.

Stay-green ranking and maturity of corn hybrids: 2. Effects on the performance of lactating dairy cows. By Arriola et al., page 975. This study examined effects of feeding corn hybrids with contrasting stay-green ranking and maturity at harvest $[27$ versus $35 \%$ dry matter (DM)] on the performance of dairy cows. Feeding the high stay-green hybrid did not affect dry matter intake or milk yield but reduced ruminal fermentation and intake of starch, crude protein, and neutral detergent fiber of hybrids harvested at $27 \% \mathrm{DM}$ and reduced DM, crude protein, and neutral detergent fiber digestibilities at both maturities. Cows fed the high stay-green diet had greater inflammatory stress and greater milk to feed ratio than those fed the low stay-green diet.

The relationship between weight, age, and average daily gain to show performance of Georgia 4-H and Future Farmers of America (FFA) commercial dairy heifers. By London et al., page 986. Studies were conducted to determine the relationship between weight, age, average daily gains, and placing in a commercial dairy heifer's performance, and to determine if these heifers are being grown according to industry guidelines. Average daily gain and placing were virtually unrelated in the commercial dairy heifer shows. No strong correlations existed for weight, age, and average daily gain, when related to placing within a class. Wither height had the highest correlation to placing. Only $36 \%$ met industry growth guidelines.
Effects of feeding strategy on milk production, reproduction, pasture utilization, and economics of autumn-calving dairy cows in eastern North Carolina. By Vibart et al., page 99\%. Grazing dairy cows in the United States require supplemental energy to allow for a greater expression of genetic potential for milk production. This 3 -yr study was performed to examine the effects of 2 feeding strategies, a combination of stocking and supplementation rates, on productive, reproductive, and financial performance of grazing, autumn-calving herds that included Holsteins, Jerseys, and crossbreds. Reproductive efficiency was similar among groups, but overall production performance and income over feed costs favored the greater stocking/ supplementation group.

Survival, lifetime production, and profitability of Normande $\times$ Holstein, Montbéliarde $\times$ Holstein, and Scandinavian Red $\times$ Holstein crossbreds versus pure Holsteins. By Heins et al., page 1011. Decreased survival and increased death loss of Holstein cows has resulted in a renewed interest in crossbreeding of dairy cattle. Normande $\times$ Holstein, Montbéliarde $\times$ Holstein, and Scandinavian Red $\times$ Holstein crossbred cows had fewer deaths and a higher percentage of cows calving a fourth time than pure Holstein cows. All crossbred groups had more projected lifetime profit per cow than pure Holstein cows, and Montbéliarde $\times$ Holstein and Scandinavian Red $\times$ Holstein cows had more projected profit per cow-day than pure Holstein cows. Crossbreds remained in herds much longer than pure Holsteins to achieve the substantial advantages for profitability. Dairy producers may improve the profitability of dairying by milking crossbred rather than purebred cows. 